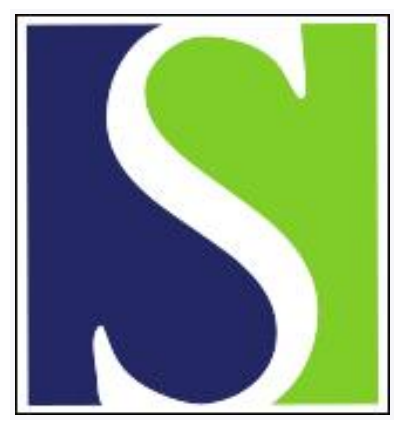

Scand J Work Environ Health 2004;30(4):322-326

https://doi.org/10.5271/sjweh.801

Issue date: Aug 2004

Prevention of acute mountain sickness by low positive end-expiratory pressure in field conditions

by Launay J-C, Nespoulos O, Guinet-Lebreton A, Besnard Y, Savourey G

Affiliation: Pôle tolérance climatique et Vêtements, Département des facteurs humains, Centre de recherches du service de santé des armées - BP 87, F-38702 La Tronche cedex, France. jclaunay@crssa.net

Key terms: acute mountain sickness; expiratory pressure; field study; high altitude environment; low barometric illness; low positive end-expiratory pressure; nonpharmacological; prevention

This article in PubMed: www.ncbi.nlm.nih.gov/pubmed/15458016 


\title{
Prevention of acute mountain sickness by low positive end-expiratory pressure in field conditions
}

\author{
by Jean-Claude Launay, MD, ${ }^{1}$ Olivier Nespoulos, MD, ${ }^{1}$ Angélique Guinet-Lebreton, Yves Besnard, MD, ${ }^{1}$ \\ Gustave Savourey, MD'
}

\begin{abstract}
Launay J-C, Nespoulos 0, Guinet-Lebreton A, Besnard Y, Savourey G. Prevention of acute mountain sickness by low positive end-expiratory pressure in field conditions. Scand J Work Environ Health 2004;30(4):322-326.
\end{abstract}

\begin{abstract}
Objectives This study evaluates the ability of positive end-expiratory pressure (PEEP), a nonpharmacological method, to prevent the occurrence of acute mountain sickness during two ascents of Mount Blanc.

Methods In a random order (once with PEEP and once without), PEEP was administered or not to eight subjects during two ascents of Mount Blanc. Scores for acute mountain sickness were quantified using the Lake Louise acute mountain sickness scoring system, and oxygen arterial blood saturation by pulse oxymetry $\left(\mathrm{SpO}_{2}\right)$, heart rate, and systolic and diastolic blood pressures were also measured.

Results The decrease in the prevalence of acute mountain sickness indicated that the PEEP system was effective, one case $(12.5 \%)$ occurring among the eight participants with PEEP and six cases $(75 \%)$ occurring among the eight without PEEP $(\mathrm{P}<0.01)$. The severity of the cases also decreased $(\mathrm{P}<0.01)$. Heart rate and blood pressure did not significantly vary, whereas the $\mathrm{SpO}_{2}$ tended to be higher with PEEP $(\mathrm{P}=0.07)$.

Conclusions This field study shows that PEEP could be an efficient method with which to prevent acute mountain sickness without adverse effects. However, the ergonomics of the PEEP system must be improved to make its use more practical in the future.
\end{abstract}

Key terms high altitude environment, low barometric illnesses, nonpharmacological, prevention.

Acute mountain sickness is an environmental disorder encountered in unacclimatized people after arrival at high altitudes, and its prevalence in the Alps varies from $9 \%$ to $69 \%$, depending on the altitude reached (1). It is characterized by headache, gastrointestinal symptoms, fatigue, weakness, dizziness, lightheadedness, and difficulty sleeping and may lead to pulmonary or cerebral edema. The prevention of acute mountain sickness is thus necessary to limit its prevalence, not only to avoid severe high altitude pathology, but also to limit physiological and psychological deterioration, especially for climbers, trekkers, or workers at high altitudes. Besides altitude acclimatization or oxygen supply, drugs such as dexamethasone (2) and acetazolamide (3) have been used to prevent acute mountain sickness. These pharmacological drugs have adverse side effects (3). Recently, Savourey et al (4) have shown that a nonpharmacological method, represented by low positive end-expiratory pressure (PEEP), is efficient in preventing acute mountain sickness in a hypobaric chamber without adverse effects. However, the efficacy of this PEEP system has yet to be evaluated at a high altitude under field conditions, which are very different from laboratory conditions. As this system appears to be very efficient in a hypobaric chamber, we hypothesized that it would also be efficient under field conditions. Consequently, the purpose of this study was to evaluate the efficacy of the PEEP system when used by eight healthy men during two randomized ascents of Mount Blanc. The ascent to Mount Blanc is well known for its ability to induce acute mountain sickness because of the high altitude reached and the rapidity of the ascent.

\section{Participants and methods}

\section{Participants}

Eight healthy male volunteers with no medical history and no acclimatization to altitude participated in the

1 Pôle tolérance climatique et vêtements (Centre of Study on Climatic Tolerance and Clothing), Département des facteurs humains, Centre de recherches du service de santé des armées (Research Centre of the Army Health Service), 38702 La Tronche cedex, France.

Reprint requests to: Dr J-C Launay, Pôle tolérance climatique et vêtements, Département des facteurs humains, Centre de recherches du service de santé des armées - BP 87, F-38702 La Tronche cedex, France. [E-mail: jclaunay@crssa.net] 
study after they signed an informed consent following a medical examination. They were regularly trained for endurance (running). The protocol was approved by the Ethics Committee of the University of Grenoble. The subjects were supervised by a physician during all the experiments. Their biometric characteristics were age 23 [standard error of the mean (SEM) 0.5] years, height 1.79 (SEM 0.04) m, weight 71.50 (SEM 4.88) kg.

\section{Postitive end-expiratory pressure}

The PEEP prototype has been described earlier (4), and it was calibrated before each experiment. Briefly, it consisted of a bi-directional valve (patent 96402315-42309 Etat français) that applied a PEEP of 5-cm $\mathrm{H}_{2} \mathrm{O}$ and was attached to a Hans Rudolf face mask with a low dead space (Hans Rudolph Inc, Kansas City, MI, USA). The characteristics of this valve were as follows: mass: $90 \mathrm{~g}$, dimensions: $6.5 \mathrm{~cm} \times 7 \mathrm{~cm}$, the level of PEEP $\left(5-\mathrm{cm} \mathrm{H}_{2} \mathrm{O}\right)$ being constant up to a flow rate of $120 \mathrm{l} / \mathrm{min}$. A 5-cm $\mathrm{H}_{2} \mathrm{O}$ level was selected because, at this pressure, the risk of barotrauma has been shown to be negligible (5).

\section{Ascents of Mount Blanc and the measurements}

The eight subjects climbed Mount Blanc twice: once with the 5-cm $\mathrm{H}_{2} \mathrm{O}$ PEEP (PEEP-5) and once without it (w-PEEP), according to a simple randomized order, determined before the experiment. Thus during the first ascent (15-16 August, day 1 and day 2, respectively), four participants were equipped with PEEP and four others were not; during the second ascent (30-31 August, day 1 and day 2, respectively), the PEEP order was reversed. This randomization permitted us to take into account possible disturbances between the two ascents (meteorological conditions, speed of ascent, etc). The time course of the two ascents was as follows. On day 1, at 1700 , the participants reached "Aiguille du Midi" (3842 m) by cable car and then the "Refuge des Cosmiques" at 1930 (3680 m). At this time, the participants were equipped with PEEP-5 until their return to "Refuge des Cosmiques" after the ascents on day 2, except during meals. They got up at 0100 on day 2 to begin the ascent. Due to bad weather, the first ascent stopped at the summit of "Mount Blanc du Tacul" (4100 m), and during the second ascent, the summit of "Mount Blanc" was reached at $1000(4810 \mathrm{~m})$. After the return to the "Refuge des Cosmiques", the participants came down to Chamonix, arriving at 1800 .

The scoring of acute mountain sickness and the physiological measurements were performed at Chamonix before the ascents, on arrival at "Refuge des Cosmiques", at bed time, on getting-up, at the highest altitude reached, on return to "Refuge des Cosmiques", and at Chamonix. The Lake Louise scoring consensus for acute mountain sickness was used by a physician who had been familiarized with the assessment of acute mountain sickness (6) and who had no interest in this study. The Lake Louise scoring system for acute mountain sickness includes the following three parts (6): (i) a self-report questionnaire with 5 items (headache, gastrointestinal symptoms, fatigue or weakness, dizziness or lightheadedness, and difficulty of sleeping, only evaluated on getting up), each rating from 0 to 3 ; (ii) a clinical assessment with three signs (mental status and ataxia rating from 0 to 4 and peripheral edema rating from 0 to 2); and (iii) an optional functional score (not used in this study). The self-report of acute mountain sickness was assessed by the physician in an interview of each participant. The clinical assessment was done by the physician, and the sum of the scores (self-report of acute mountain sickness plus clinical assessment) was determined for each participant. A score of $\geq 3$ points for the self-report or a combination of the $\geq 3$ points with the results of the clinical assessment was reported as representative of acute mountain sickness (6). Heart rate and oxygen arterial blood saturation by pulse oxymetry $\left(\mathrm{SpO}_{2}\right)$ were measured at the level of an index finger (ONYX 9500, Nonin Medical Inc, MN, USA). Systolic and diastolic arterial blood pressures were measured manually by the physician with a sphygmomanometer (Brassard Integral, Colson, Garges-les-Gonesse, France). All of these measurements were taken at the same time as the scoring of acute mountain sickness. Microhematocrit was determined at Chamonix before and at the end of the two ascents.

\section{Statistical analysis}

The main effects of time and the PEEP (PEEP-5 and wPEEP), as well as their interactions, were analyzed with an analysis of variance (ANOVA) for repeated measures using the scores for acute mountain sickness and the physiological data. When the interactions of the effects were not significant, the main effect has been given. When the interactions of the effects were significant, post hoc Tukey tests were performed to locate the significant differences. The prevalances of acute mountain sickness with and without PEEP were calculated and then compared using a chi-square test. The microhematocrit values were analyzed with a one-way ANOVA (using PEEP as the source of variation). A PEEP $\times$ time ANOVA with the participants divided into two groups $(\mathrm{N}=4$ in each group), according to whether they received the PEEP (PEEP-5 or w-PEEP) during the first ascent (one group) or during the second ascent (second group) was performed to study the PEEP treatment $\times$ ascent effect. Statistica for Windows ${ }^{\circledR}$ (Statsoft France, Maisons-Alfort, France) was used for the statistical analysis. The null 
hypothesis was rejected at $\mathrm{P} \leq 0.05$. The results have been presented as means and standard errors of the means.

\section{Results}

All eight men participated in both ascents, and no severe medical problem, such as high altitude pulmonary or cerebral edema, was encountered. No data were missed, except those for $\mathrm{SpO}_{2}$ at the summit because of technical problems.

The analysis of the effect of the PEEP treatment $x$ ascent for the various variables, in order to determine whether the participants who received PEEP-5 for their first ascent performed differently from those who received PEEP-5 for their second ascent showed any significant difference even though the first ascent stopped at the summit of "Mount Blanc du Tacul" (4100 m) and the second ascent stopped at the summit of "Mount Blanc" (4810 m). This analysis was carried out in a similar manner for w-PEEP, which also showed no significant difference.

Without PEEP, the highest self-report scores for each participant varied between 0 and 6 , three participants had a score of 3 , two participants were given a score of 4 , and one had a score of 6 , for a proportion of 6 to 8 with acute mountain sickness $(75 \%)$. With PEEP, the highest self-report scores for each participant varied between 0 and 3 , only one subject being given a score of 3 , for a proportion of 1 to 8 with acute mountain sickness $(12.5 \%)$. The difference between the two conditions was statistically significant $(\mathrm{P}<0.01)$ (table 1$)$. The mean self-report scores and mean self-report scores plus the clinical examination scores were lower with PEEP both at the summit $(\mathrm{P}<0.01)$ and at the return to "Cosmiques" $(\mathrm{P}<0.05)$ (table 1). The participants' heart rate, systolic and diastolic blood pressures, and microhematocrit were unchanged by PEEP. The $\mathrm{SpO}_{2}$ decreased during the ascents $(\mathrm{P}<0.01)$ but tended to be higher with PEEP $(\mathrm{P}=0.07)$ (table 2).

\section{Discussion}

Despite a large variability in the scores of the participants, this study showed that a rapid ascent of Mount Blanc induces a high risk of acute mountain sickness since the prevalence observed was $75 \%$ for the participants without PEEP. This higher prevalence, compared with data in the literature, especially those of Maggiorini et al (1), can be explained by the rapid ascent to a high altitude by the cable car of "Aiguille du Midi", which is a high risk factor for the development of acute mountain sickness. However, no serious medical problems were encountered despite poor meteorological conditions during the first ascent, attesting that experiments conducted under field conditions are sometimes difficult and expose participants to potential medical disorders. In this study, we did not consequently include a true placebo group (PEEP valve with $0-\mathrm{cm}_{2} \mathrm{O}$ ), first to ensure the safety of the participants exposed to severe environmental conditions encountered at a high altitude and second to avoid high altitude acclimatization due to repetitive ascents. For this last reason, the participants were divided into two groups according to random order (PEEP-5 and w-PEEP) for the two ascents to avoid possible interactions between PEEP and altitude acclimatization. This randomization also permitted us to

Table 1. Acute mountain sickness scores with (PEEP-5) or without (w-PEEP) positive end-expiratory pressure. (SEM = standard error of the mean, NS = not significant)

\begin{tabular}{|c|c|c|c|c|c|c|c|c|c|c|c|c|c|c|}
\hline & \multicolumn{2}{|c|}{$\begin{array}{l}\text { Departure } \\
\text { (Chamonix) }\end{array}$} & \multicolumn{2}{|c|}{$\begin{array}{c}\text { Arrival } \\
\text { (Cosmiques) }\end{array}$} & \multicolumn{2}{|c|}{$\begin{array}{c}\text { Bedtime } \\
\text { (Cosmiques) }\end{array}$} & \multicolumn{2}{|c|}{$\begin{array}{l}\text { Getting up } \\
\text { (Cosmiques) }\end{array}$} & \multicolumn{2}{|c|}{ Summit } & \multicolumn{2}{|c|}{$\begin{array}{c}\text { Return } \\
\text { (Cosmiques) }\end{array}$} & \multicolumn{2}{|c|}{$\begin{array}{c}\text { Return } \\
\text { (Chamonix) }\end{array}$} \\
\hline & Mean & SEM & Mean & SEM & Mean & SEM & Mean & SEM & Mean & SEM & Mean & SEM & Mean & SEM \\
\hline \multicolumn{15}{|c|}{ Self-report of acute mountain sickness } \\
\hline w-PEEP & 0.38 & 0.47 & 0.75 & 0.75 & 1.63 & 1.28 & 2.00 & $2.00^{a}$ & 3.13 & $1.16^{b}$ & 2.38 & $1.28^{b}$ & 0.88 & 0.66 \\
\hline PEEP-5 & 0.00 & 0.00 & 1.00 & 0.75 & 1.00 & 0.75 & 2.00 & $0.75^{b}$ & 1.50 & $0.88^{a}$ & 1.63 & $0.72^{a}$ & 0.75 & 0.75 \\
\hline P-value ${ }^{c}$ & \multicolumn{2}{|c|}{ NS } & \multicolumn{2}{|c|}{ NS } & \multicolumn{2}{|c|}{ NS } & \multicolumn{2}{|c|}{ NS } & \multicolumn{2}{|c|}{$P<0.01$} & \multicolumn{2}{|c|}{$P<0.05$} & \multicolumn{2}{|c|}{ NS } \\
\hline \multicolumn{15}{|c|}{ Clinical assessment scores } \\
\hline w-PEEP & 0.00 & 0.00 & 0.00 & 0.00 & 0.00 & 0.00 & 0.25 & 0.38 & 0.50 & 0.75 & 0.13 & 0.22 & 0.00 & 0.00 \\
\hline PEEP-5 & 0.00 & 0.00 & 0.13 & 0.22 & 0.13 & 0.22 & 0.00 & 0.00 & 0.00 & 0.00 & 0.13 & 0.22 & 0.00 & 0.00 \\
\hline P-value ${ }^{c}$ & \multicolumn{2}{|c|}{ NS } & \multicolumn{2}{|c|}{ NS } & \multicolumn{2}{|c|}{ NS } & \multicolumn{2}{|c|}{ NS } & \multicolumn{2}{|c|}{$P<0.01$} & \multicolumn{2}{|c|}{ NS } & \multicolumn{2}{|c|}{ NS } \\
\hline \multicolumn{15}{|c|}{ Self-report of acute mountain sickness plus clinical assessment scores } \\
\hline w-PEEP & 0.38 & 0.47 & 0.75 & 0.75 & 1.63 & 1.28 & 2.25 & $2.38^{a}$ & 3.63 & $1.63^{b}$ & 2.50 & $1.38^{a}$ & 0.88 & 0.66 \\
\hline PEEP-5 & 0.00 & 0.00 & 1.13 & 0.91 & 1.13 & 0.91 & 2.00 & $0.75^{a}$ & 1.50 & 0.88 & 1.76 & $0.63^{a}$ & 0.75 & 0.75 \\
\hline P-value ${ }^{c}$ & \multicolumn{2}{|c|}{ NS } & \multicolumn{2}{|c|}{ NS } & \multicolumn{2}{|c|}{ NS } & \multicolumn{2}{|c|}{ NS } & \multicolumn{2}{|c|}{$P<0.01$} & \multicolumn{2}{|c|}{$P<0.05$} & \multicolumn{2}{|c|}{ NS } \\
\hline
\end{tabular}

a $\mathrm{P}<0.05$, in comparison with the departure value.

b $\mathrm{P}<0.01$, in comparison with the departure value.

c Between with and without PEEP at the same time of day or night. 
Table 2. Physiological measurements with (PEEP-5) and without ( $w$-PEEP) positive end-expiratory pressure. (SEM = standard error of the mean, NS = not significant)

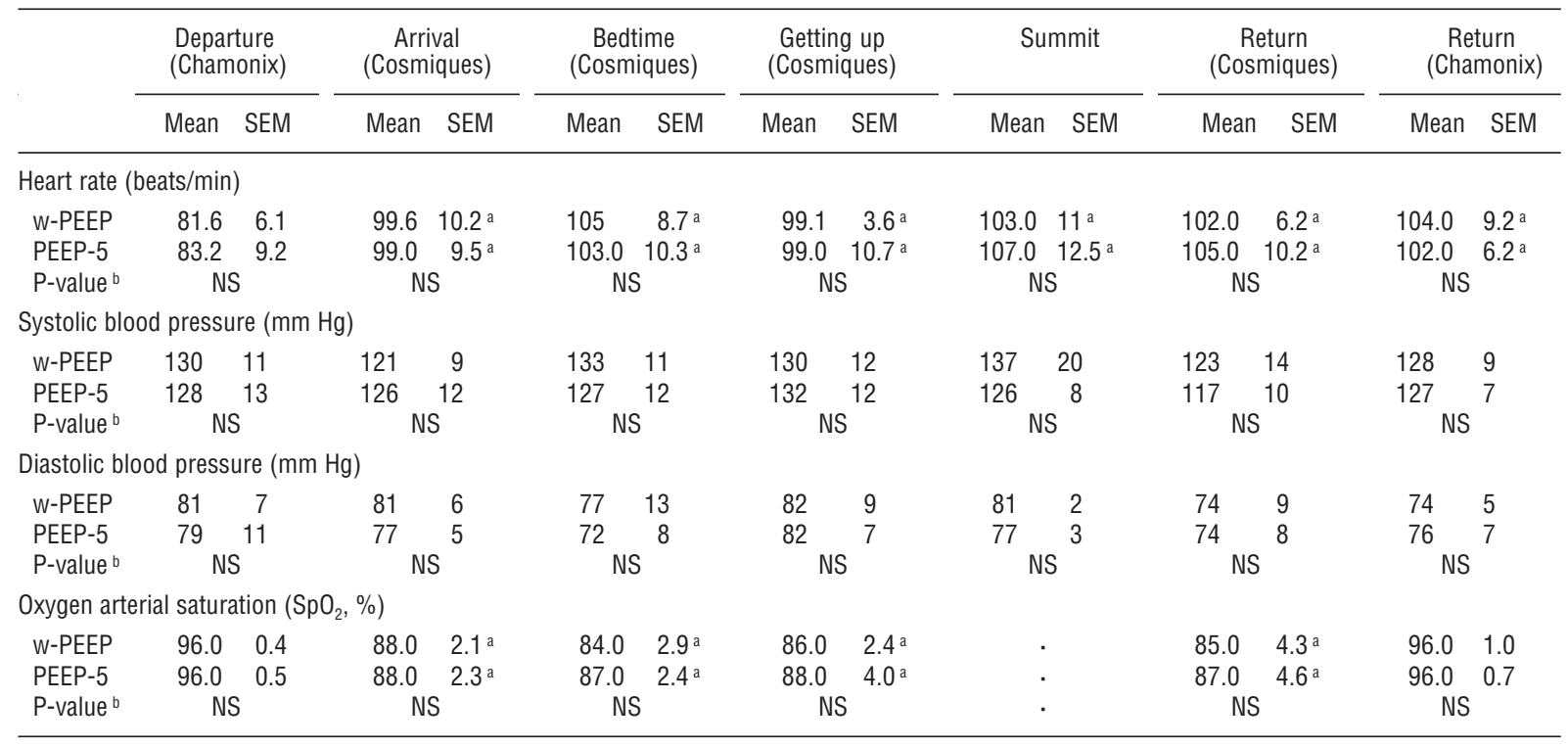

a $P<0.01$, in comparison with the departure value.

${ }^{b}$ Between with and without PEEP at the same time of day or night.

take into account the various experimental field conditions. However, no significant changes in the variables were found between the PEEP-5 treatment during the first and second ascents as for w-PEEP. Consequently, it was possible to group the participants for the same treatment in order to compare the scores for acute mountain sickness and the physiological variables between PEEP-5 and w-PEEP to evaluate both the efficacy of the PEEP prototype system for preventing acute mountain sickness and its physiological consequences.

The results showed that the PEEP-5 prototype system appears to be efficient in preventing acute mountain sickness under field conditions without adverse medical effects, as shown by the differences in the prevalence of acute mountain sickness $(\mathrm{P}<0.01)$, and they therefore confirmed the results obtained in the laboratory (4). This effectiveness is also supported by the lower mean score for acute mountain sickness and the lower highest self-report scores observed with PEEP-5 at the summit $(\mathrm{P}<0.01)$, which attested that both the prevalence and severity of acute mountain sickness decreased with PEEP-5. However, the PEEP-5 system sometimes involves difficulties to sleep or speak, and expired water vapor tends to condense, freeze, and lock the PEEP valve, and therefore the ergonomics of this prototype must be improved. The physiological mechanisms underlying the effectiveness of the PEEP-5 used in this study are difficult to explain because the physiological measurements during this experiment were limited due to the high altitude conditions. However, $\mathrm{SpO}_{2}$ with PEEP-5 tends to be higher $(\mathrm{P}=0.07)$, and this higher value suggests better arterial blood oxygenation. This observation may be related to an increase in alveolar ventilation, as reported by Savourey et al (7) in their study using the same system under laboratory conditions. The absence of a significant change in heart rate and in arterial blood pressure attests that the PEEP-5 system does not modify the cardiac variables, as also reported by Savourey et al $(4,7,8)$. In the same way, the PEEP-5 system in our experiment did not affect microhematocrit after the ascent of Mount Blanc.

In conclusion, this study showed that low PEEP is an efficient nonpharmacological method for preventing acute mountain sickness under field conditions at high altitudes without any adverse medical effects. In the future, it will be necessary first to confirm these results in larger studies, second to better clarify the physiological mechanisms involved, and third to determine the best conditions for the use of this system in practice (intermittent or continuous carrying, use only by persons susceptible to acute mountain sickness, etc). The PEEP system could be used by climbers, high altitude guides, hikers, and rescue teams or during occupational activities at high altitudes after the ergonomics of this prototype are improved for speaking and, eventually, for sleeping.

\section{Acknowledgments}

We gratefully thank the men who participated in the study and Médecin-Général Inspecteur Seigneuric, Director of the ESSA-Lyon Bron (France). We also thank Richard Catérini, who directly participated in the design 
of the PEEP system. This study was supported by a grant (98019-S) from the Mission pour le Développement de L'innovation Participative (Mission Innovation, Délégation générale à l'Armement, Paris, France). Special thanks are extended to Médecin Général J Bittel and AM Hanniquet.

\section{References}

1. Maggiorini M, Buhler B, Walter M, Oelz O. Prevalence of acute mountain sickness in the Swiss Alps. BMJ 1990;301(6756):853-5.

2. Hackett PH, Roach RC, Wood RA, Foutch RG, Meehan RT, Rennie D, et al. Dexamethasone for prevention and treatment of acute mountain sickness. Aviat Space Environ Med 1988;59(10):950-4.

3. Greene MK, Kerr AM, McIntosh IB, Prescott RJ. Acetazolamide in prevention of acute mountain sickness: a doubleblind controlled cross-over study. Br Med J Clin Res
1981;283(6295):811-3.

4. Savourey G, Caterini R, Launay JC, Guinet A, Besnard Y, Hanniquet AM, et al. Positive end expiratory pressure as a method for preventing acute mountain sickness. Eur J Appl Physiol 1998;77(1-2):32-6.

5. Schoene RB. Positive end expiratory pressure as a method of treating high altitude pulmonary edema. J Wild Med 1993;4:340-1.

6. Roach RC, Bärtsch P, Hackett PH, Oelz O. The Lake Louise acute mountain sickness scoring system. In: Sutton JR, Coates G, Houston C, editors. Hypoxia and molecular medicine; 1993/02/09-13; Lake Louise, Alberta, Canada. Burlington (VT): Queen City Printers Inc; 1993. p 272-4.

7. Savourey G, Besnard Y, Launay JC, Guinet A, Hanniquet AM, Caterini R, et al. Short hypobaric hypoxia and breathing pattern: effect of positive end expiratory pressure. Aviat Space Environ Med 1999;70(9):863-6.

8. Savourey G, Besnard Y, Launay JC, Guinet A, Hanniquet $\mathrm{AM}$, Sendowski I, et al. Positive end expiratory pressure (PEEP) slightly modifies ventilatory response during incremental exercise. Aviat Space Environ Med 2001;72(1):21-4.

Received for publication: 24 October 2003 